\title{
Will global warming undo the hard-won gains of prevention of mother-to-child transmission of HIV?
}

During pregnancy, women have a markedly diminished ability to tolerate heat stress. ${ }^{[1]}$ Increased internal heat production due to fetal growth and metabolism occurs alongside a reduced capacity to dissipate heat, stemming from fat deposition and a decreased ratio of body surface area to body mass. Heat intolerance of pregnant women is exacerbated by rises in ambient temperature, particularly during heatwaves. By implication, pregnant women and developing fetuses may be especially susceptible to the unfolding impacts of global warming. Globally temperatures are already rising, and future increments in southern Africa are expected to be twice the global rate. $^{[2]}$

Many studies have linked heat exposure during pregnancy to a range of adverse birth outcomes, including prematurity, stillbirth, low birth weight and congenital defects. ${ }^{[3-5]}$ Although less is known about the effects of heat on maternal health, associations have been reported with antepartum haemorrhage, hypertension, genital infections, and mental health conditions such as anxiety and depression. ${ }^{[4,6,7]}$ There are very few studies in Africa, ${ }^{[8]}$ where heat sensitivity may be even greater given that few women can afford air conditioning or other adaptation measures. Labour wards in the public sector in South
Africa (SA) also seldom have air conditioning, and temperatures in some facilities can exceed outdoor temperatures by as much as $4^{\circ} \mathrm{C} . .^{[9]}$

There are numerous self-reinforcing and bidirectional interactions between HIV and climate change. ${ }^{[10]}$ These impact directly on the health of HIV-infected people, but also on the socioeconomic determinants of HIV transmission, such as migration, gender inequities and poverty. Given mounting evidence of HIV-climate interactions, connecting heat exposure and risks of mother-to-child transmission (MTCT) of HIV may not be as implausible as it might first appear (Fig. 1).

Just as the causes of low birth weight and preterm birth are complex, so too are the reasons why some children but not others acquire HIV. Overwhelmingly, however, the most important factor affecting risk of MTCT is whether a woman receives and adheres to antiretroviral treatment. Extreme weather events, such as floods and wildfires, could undermine already fragile drug supply systems in SA. The mental health effects of hot weather and other consequences of climate change are considerable - though under-appreciated - and may well worsen drug adherence during the postpartum period, for example. ${ }^{[11]}$ Obstetric factors remain important determinants of

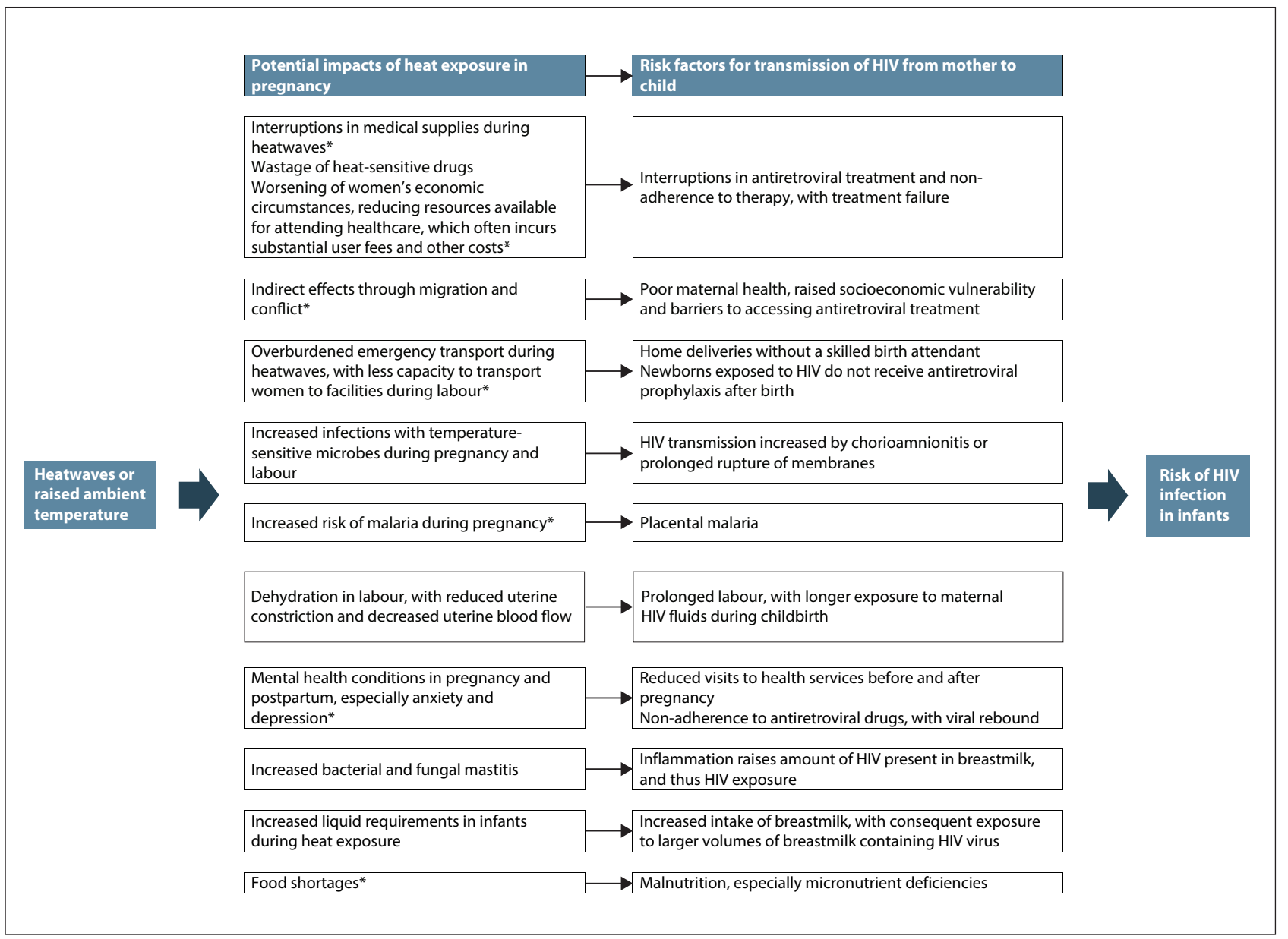

Fig. 1. Potential pathways between climate change and risk of mother-to-child transmission of HIV and other adverse birth outcomes. ${ }^{*}$ These impacts may also be caused by other manifestations of climate change, such as wildfires, storms, flooding and droughts.) 
MTCT, especially in women who have not had HIV testing during pregnancy. Five percent of pregnant women in SA do not attend antenatal care, and the figure is considerably higher in some highrisk settings. ${ }^{[12,13]}$ The outcomes of hot weather in pregnancy, such as prematurity, prolonged rupture of membranes and genital infections, are important risk factors for MTCT. ${ }^{[14,15]}$ Additionally, during hot weather infants' intake of breastmilk is raised, increasing the total amount of HIV virus the infant is exposed to. Mastitis, which may occur given the close ties between raised temperatures and infection, is also a risk factor for MTCT. ${ }^{[15,16]}$

It would be possible to assess these putative associations between temperature and MTCT using the large data sets on the HIV status of infants and the detailed meteorological data in SA. Similarly, connections between temperature and birth outcomes could be analysed using existing data sets. There are some complexities in these analyses, as there is no established critical window period of maternal sensitivity to hot temperatures, and it is not known whether drivers of adverse outcomes relate to levels or duration of heat exposure, or to temperature thresholds. Heat exposures may have immediate impacts on pregnancy, delayed (lagged) or cumulative effects, or a combination thereof.

Attribution studies connecting heat exposure to adverse birth outcomes and HIV infection in infants could have far-reaching implications. These findings could support measures such as increased natural ventilation and air conditioning in labour wards, prioritisation of hydration during labour, and the setting of specific heat-warning thresholds and plans for pregnant women. Evidence may also support arguments for building resilience in pregnant women by, for example, commencing the child support grant in pregnancy, rather than postpartum. ${ }^{[17]}$

Estimates of the effect of heat exposure on birth outcomes could inform estimates of the burden of disease attributable to climate change in sub-Saharan Africa, a major evidence gap. The 2017 Global Burden of Disease report ${ }^{[18]}$ presents data on an array of diseases and environmental exposures, but makes no mention of climate change impacts - a glaring omission, possibly symptomatic of the non-involvement of most public health professionals in this rapidly emerging field. Quite rightly, adverse birth outcomes contribute many person-years lost in burden of disease estimates.

In conclusion, it is possible that global warming could undo the considerable gains made by prevention of MTCT programmes, and it will almost certainly have a notable impact on birth outcomes in the country. Such impacts bring into focus the practical actions required to support climate-conscious economic development, especially in the energy sector. Moreover, as has occurred many times in the past, focusing on harms to children may well be the best strategy to galvanise public health practitioners to action in the climate change arena.
Acknowledgements. I thank members of the Maternal Health and Climate Change Research Group for their contribution to this work.

\section{Matthew Chersich}

Wits Reproductive Health and HIV Institute, Faculty of Health Sciences, University of the Witwatersrand, South Africa

mchersich@wrhi.ac.za

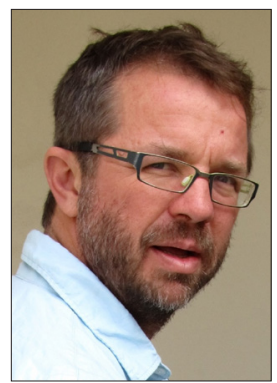

1. Kuehn L McCormick S. Heat exposure and maternal health in the face of climate change. Int J Environ Res Public Health 2017;14(8):853. https://doi.org/10.3390/ijerph14080853

2. Engelbrecht $\mathrm{F}$, Adegoke J, Bopape M, et al. Projections of rapidly rising surface temperatures over Africa under low mitigation. Environ Res Lett 2015;10(8). https://doi.org/10.1088/1748-9326/10/8/085004 Arbuthnott KG, Hajat $S$. The health effects of hotter summers and heat waves in the population of the United Kingdom: A review of the evidence. Environ Health 2017;16(Suppl 1):119. https://doi. org/10.1186/s12940-017-0322-5

4. Cil G, Cameron TA. Potential climate change health risks from increases in heat waves: Abnormal birth outcomes and adverse maternal health conditions. Risk Anal 2017;37(11):2066-2079. https:// doi.org/10.1111/risa.12767

5. Benmarhnia T, Auger N, Stanislas V, Lo E, Kaufman JS. The relationship between apparent temperature and daily number of live births in Montreal. Matern Child Health J 2015;19(12):2548-2551. https://doi. org/10.1007/s10995-015-1794-y

6. Dadvand P, Basagana X, Figueras F, Sunyer J, Nieuwenhuijsen MJ. Climate and group B streptococci colonisation during pregnancy: Present implications and future concerns. BJOG 2011;118(11):13961400. https://doi.org/10.1111/j.1471-0528.2011.03044.x

7. Lin $\mathrm{YF}, \mathrm{Hu} \mathrm{WJ}, \mathrm{Xu}$ J, et al. Association between temperature and maternal stress during pregnancy. Environ Res 2017;158:421-430. https://doi.org/10.1016/j.envres.2017.06.034

8. Asamoah B, Kjellstrom T, Ostergren PO. Is ambient heat exposure levels associated with miscarriage or stillbirths in hot regions? A cross-sectional study using survey data from the Ghana Maternal Health Survey 2007. Int J Biometeorol 2018;62(3):319-330. https:// doi.org/10.1007/s00484-017-1402-5

9. Wright CY, Street RA, Cele N, et al. Indoor temperatures in patient waiting rooms in eight rural primary health care centers in northern South Africa and the related potential risks to human health and wellbeing. Int J Environ Res Public Health 2017;14(1):43. https://doi.org/10.3390/ijerph14010043 10. Talman A, Bolton S, Walson JL. Interactions between HIV/AIDS and the environment: Toward Talman A, Bolton S, Walson IL. Interactions between HIV/AIDS and the environment: Toward a syndemic fran

11. Nachega JB, Uthman OA, Anderson J, et al. Adherence to antiretroviral therapy during and after pregnancy in low-income, middle-income, and high-income countries: A systematic review and meta-
s. pregnancy in low-income, middle-income, and high-income countries: A systematic review and meta-

12. Statistics South Africa. South Africa Demographic and Health Survey 2016: Key Indicator Report. Pretoria: Stats SA, 2017. https://www.statssa.gov.za/publications/Report\%2003-00-09/Report\%2003Pretoria: Stats SA, 2017. https://www

13. Gumede S, Black V, Naidoo N, Chersich MF. Attendance at antenatal clinics in inner-city Johannesburg, . Gumede S, Black V, Naidoo N, Chersich MF. Attendance at antenatal clinics in inner-city Johannesburg,
South Africa and its associations with birth outcomes: Analysis of data from birth registers at three facilities. BMC Public Health 2017;17(Suppl 3):443. https://doi.org/10.1186/s12889-017-4347-z

14. World Health Organization/Joint United Nations Programme on HIV and AIDS. HIV in pregnancy: A review. WHO/RHT/98.24, UNAIDS/98.44. http://www.unaids.org/sites/default/files/media_asset/ jc151-hiv-in-pregnancy_en_1.pdf (accessed 1 April 2019).

15. Gumbo FZ, Duri K, Kandawasvika GQ, et al. Risk factors of HIV vertical transmission in a cohort of women under a PMTCT program at three peri-urban clinics in a resource-poor setting. J Perinatol 2010;30(11):717-723. https://doi.org/10.1038/jp.2010.31

16. Lunney KM, Iliff $P$, Mutasa $K$, et al. Associations between breast milk viral load, mastitis, exclusive breast-feeding, and postnatal transmission of HIV. Clin Infect Dis 2010;50(5):762-769. https://doi. org/10.1086/650535

17. Chersich MF, Luchters S, Blaauw D, et al. Safeguarding maternal and child health in South Africa by starting the Child Support Grant before birth: Design lessons from pregnancy support programmes in 27 countries. S Afr Med J 2016;106(12):1192-1210. https://doi.org/10.7196/SAMJ.2016.v106.112.12011

18. GBD 2017 Risk Factor Collaborators. Global, regional, and national comparative risk assessment of 84 behavioural, environmental and occupational, and metabolic risks or clusters of risks for 195 countries and territories, 1990 - 2017: A systematic analysis for the Global Burden of Disease Study 2017. Lancet 2018;392(10159):1923-1994. https://doi.org/10.1016/S0140-6736(18)32225-6

S Afr Med J 2019;109(5):287-288. DOI:10.7196/SAMJ.2019.v109i5.13988 